\title{
A Sala de Aula Invertida Ressignificada no Contexto do Ensino Remoto de Robótica para Formação de Professores
}

\author{
Title: The Reassigned Flipped Classroom in the Context of Remote Robotics Teaching for \\ Teacher Education
}

Jussara Pinto Pancieri

Instituto Federal do Espírito Santo

jussara.pancieri11@gmail.com

Márcia Gonçalves de Oliveira

Instituto Federal do Espírito Santo

marcia.oliveira@ifes.edu.br

\author{
Bruno Porto \\ Instituto Federal do Espírito Santo \\ brunnoporto@gmail.com \\ Vanessa Battestin \\ Instituto Federal do Espírito Santo \\ vanessa@ifes.edu.br
}

\begin{abstract}
Resumo
A Robótica Educacional é um campo relativamente novo que tem potencial de aproximar a realidade do aluno com os conteúdos educacionais, principalmente quando se utilizam metodologias de aprendizagem ativa e integram-se múltiplas áreas de conhecimentos. Nessa perspectiva, diante da carência de soluções de formação de professores em computação e automação, apresentamos neste trabalho uma Oficina Online de Introdução à Robótica Educacional para formação de professores. O objetivo dessa oficina foi promover uma reflexão e reorientação de estratégias de inovação para as práticas educativas preparando professores para a mediação de uma aprendizagem criativa a partir dos conceitos do Pensamento Computacional no desenvolvimento de pequenos projetos robóticos. Essa proposta foi pensada com a metodologia de Sala de Aula Invertida, mas devido à impossibilidade de realização de atividades presenciais por causa da pandemia de Covid-19, ressignificamos o uso dessa metodologia para um o contexto de ensino remoto de Robótica Educacional. Dessa forma, a formação de professores foi realizada totalmente online com atividades distribuidas em momentos síncronos e assíncronos com as práticas de robótica no simulador online Tinkercad. Os resultados obtidos apontam para pontos relevantes da prática de ensino remoto de robótica que poderão impactar positivamente no processo de aprendizagem dos alunos, uma vez que as práticas em robótica levaram à compreensão e à reflexão dos passos na resolução de problemas a partir do Pensamento Computacional.
\end{abstract}

Palavras-Chaves: Formação de Professores; Robótica Educacional; Sala de Aula Invertida; Metodologias Ativas.

\begin{abstract}
Educational Robotics is a relatively new field that has the potential to bring the student's reality closer to educational content, especially when active learning methodologies are used and multiple areas of knowledge are integrated. In this perspective, given the lack of teacher training solutions in computing and automation, we present in this work an Online Workshop on Introduction to Educational Robotics for teacher training. The objective of this workshop was to promote a reflection and reorientation of innovation strategies for educational practices, preparing teachers to mediate creative learning from the concepts of computational thinking in the development of small robotic projects. This proposal was designed with the Flipped Classroom methodology, but due to the impossibility of performing face-to-face activities because of the Covid-19 pandemic, we redefine the use of this methodology for one for the context of remote teaching of Educational Robotics. In this way, teacher training was carried out entirely online with activities distributed in synchronous and asynchronous moments and with the robotics practices carried out in the Tinkercad online simulator. The results obtained point to relevant points in the practice of remote teaching of robotics that may have a positive impact on the students' learning process, since the practices in robotics led to the understanding and reflection of the steps in solving problems based on Computational Thinking.
\end{abstract}

Keywords: Teacher Training; Educational Robotics; Flipped Classroom; Active Methodologies.

Cite as: Pancieri, J.P., Porto, B., Oliveira, M.G., \& Battestin, V. (2020). The Reassigned Flipped Classroom in the Context of Remote Robotics Teaching for Teacher Education (A Sala de Aula Invertida Ressignificada no Contexto do Ensino Remoto de Robótica para Formação de Professores). Brazilian Journal of Computers in Education (Revista Brasileira de Informática na Educação - RBIE), 29, 440-455. DOI: 10.5753/RBIE.2021.29.0.440 


\section{Introdução}

Desde a última década, a robótica tem atraído o interesse de docentes e pesquisadores enquanto um recurso tecnológico para o desenvolvimento das habilidades sociais em discentes de diversos níveis do ensino (ALIMISIS, 2013). De acordo com Lima (2016), a robótica também está cada vez mais presente em outros contextos, a saber: na medicina para realizar cirurgias, em tarefas diárias, em atividades de entretenimentos, na indústria, em laboratórios químicos, em pesquisas espaciais e em muitas outras áreas de conhecimentos.

Por meio da robótica os alunos são capazes de explorar novas ideias e descobrir novos caminhos na aplicação de conhecimentos adquiridos em sala de aula e na resolução de problemas, desenvolvendo as habilidades de criar hipóteses, examinar soluções, estabelecer relações e obter conclusões (QUEIROZ e SAMPAIO, 2016).

Papert (1994) também destaca que, além da mudança tecnológica, o ambiente escolar deve ainda redefinir métodos e técnicas para que o professor possa inovar. Por isso, algumas estratégias de inovação devem ser implementadas pelos professores a fim de formular/reformular suas práticas educativas e atender às transformações que ocorrem com chegada das tecnologias. A robótica que vem sendo inserida em contextos educacionais como um instrumento efetivo de reflexão e ação diante dos processos do pensar computacionalmente, de montar estruturas robóticas e de programar mecanismos que contribuem para o desenvolvimento de habilidades para a nova geração de estudantes que já convive com as tecnologias digitais.

De acordo com Bacich e Moran (2018), a Sala de Aula Invertida é uma estratégia ativa de um modelo híbrido, que aprimora o tempo da aprendizagem. Nessa estratégia, uma parte do processo de aprendizagem é do aluno e pode acontecer tanto antes de um encontro coletivo em sala de aula (aula invertida) quanto em atividades do pós-aula (BACICH e MORAN, 2018, p. 11).

Entretanto, diante do atual contexto mundial de pandemia de COVID-19, os ambientes educacionais têm sofrido grandes impactos com o distanciamento social, o que impossibilita as aulas presenciais e força uma realidade educacional de ensino remoto. Dessa forma, neste tempo de indefinições e restrições, é preciso ressignificar estratégias e tecnologias de ensino para um contexto educacional totalmente online. Assim, este artigo apresenta uma proposta de ressignificação da metodologia de ensino híbrido Sala de Aula Invertida para o ensino remoto de Robótica Educacional, com a proposta de distribuir em momentos síncronos e assíncronos o estudo e prática de um processo de formação de professores.

Para isso, realizamos essa formação de professores nas plataformas Moodle, Tinkercad e na plataforma de webconferências da Rede Nacional de Ensino e Pesquisa (RNP). No ambiente Moodle, os momentos assíncronos foram utilizados para o estudo dos conteúdos, por meio de materiais textuais e vídeoaulas, para a prática de exercícios, para o uso do simulador Tinkercad e para as discussões em fóruns. No Tinkercad, em momentos síncronos e assíncronos, foram desenvolvidos pequenos projetos de Robótica Educacional. Na plataforma de webconferência RNP, em momentos síncronos, houve explanação dos conteúdos, discussão de atividades, prática no simulador Tinkercad e atendimento aos alunos com dúvidas.

Para desenvolver essa proposta de ensino, levantamos a seguinte questão de pesquisa: como impactar a prática educativa dos professores ressignificando a metodologia de sala de aula invertida em momentos síncronos e assíncronos de ensino remoto de Robótica Educacional para a formação de professores? Para responder a essa questão de pesquisa, estabelecemos como metas: apresentar um novo olhar quanto à utilização da robótica na educação por meio da ressignificação da Sala de Aula Invertida no contexto de ensino remoto e contribuir para práticas pedagógicas em uma ação de formação continuada de professores. Com essas metas, temos como objetivo principal promover uma reflexão e reorientação de estratégias de inovação para as práticas 
educativas, preparando professores para a mediação de uma aprendizagem criativa a partir dos conceitos do Pensamento Computacional no desenvolvimento de pequenos projetos robóticos.

Dentro da proposta de ressignificação da Sala de Aula Invertida, os espaços "em casa" e "em sala de aula" da Sala de Aula Invertida Bergmann e Sams (2018) são contextualizados, respectivamente, no modo síncrono, na plataforma de webconferência RNP e, no modo assíncrono, no ambiente virtual de aprendizagem Moodle, ambos em plataformas online.

A Sala de Aula Invertida, em modos síncronos e assíncrono, embora já tenha sido comtemplada em outras áreas de conhecimento (REHMAN, 2021) e em estratégias de ensino de robótica, tais estratégias ainda não foram validadas em aulas de robótica (GOMES et al., 2020). Dessa forma, este trabalho avança ao aplicar e validar a metodologia de Sala de Aula Invertida em uma oficina de Robótica Educacional, ofertada para professores, desenvolvida totalmente online, comtemplando momentos síncronos e assíncronos e com uso de simulador robótico (TSELEGKARIDIS e SAPOUNIDIS, 2021).

Portanto, a principal contribuição deste trabalho para a Informática na Educação, considerando o atual contexto de pandemia de Covid-19, em que se demandam estratégias de ensino para não interromper as aulas, é ressignificar, no contexto de ensino remoto de robótica, a estratégia de ensino híbrido de Sala de Aula Invertida, desenvolvendo-a em momentos síncronos e assíncronos com práticas de robótica em simulador online.

\section{Fundamentação Teórica}

No levantamento de literatura relacionada, aponta-se um enorme crescimento no campo da pesquisa e da prática quanto à inserção da robótica na educação, que vem se destacando com um grande potencial para impactar em diferentes áreas do conhecimento (CAMPOS, 2019). Essa concepção de uso da robótica na educação se baseia fortemente na Teoria Construcionista de Seymour Papert, sendo influenciada pela Teoria Construtivista de Jean Piaget.

Seymour Papert foi o primeiro homem a aplicar robôs na educação propondo uma abordagem de aprendizagem em sala de aula que ele chama de "construcionismo", em oposição ao estilo tradicional de "instrucionismo". Segundo Papert (1997), a atitude construcionista tem como meta ensinar de forma a produzir uma melhor aprendizagem, uma vez que os alunos constroem algo, podendo aprender a programar, bem como a conceber e montar seus próprios robôs.

O trabalho pioneiro de Seymourt Papert, durante a década de 1980, mostrou que crianças pequenas poderiam aprender a linguagem de programação LOGO e a codificar os robôs do tipo tartaruga para resolver problemas. Dentro dessa proposta, Papert (1993) acreditava que as atividades auxiliadas por robôs possuíam grande potencial para melhorar o ensino em sala de aula, uma vez que a criança aprende melhor quando está ativamente envolvida na construção de objetos.

A partir dessa abordagem, os robôs educacionais começaram então a fornecer oportunidades para o envolvimento de alunos, mesmo em idade precoce, em atividades de codificação (isto é, programação) e de não-codificação (isto é, de criatividade e abstração) da Ciência da Computação, aplicando conceitos do Pensamento Computacional. Além disso, conforme Queiroz e Sampaio (2016), a Robótica Educacional permite à criança pensar em um problema, buscar soluções, criar, manipular e controlar diversos objetos concretos e, por meio deles, criar os comandos por um computador em um processo no qual se estabelece a construção do conhecimento.

Nessa perspectiva, para o contexto de formação de professores, consideramos importante a abordagem de aprendizagem ativa desenvolvida por Papert por contemplar o uso da Robótica Educacional a partir de objetivos direcionados para a resolução de problemas e para o desenvolvimento das habilidades do Pensamento Computacional nos processos de aprendizagem. 
A robótica aplicada no contexto educacional vem, dessa forma, apresentando-se como um recurso tecnológico com a finalidade de fortalecer o processo de ensino e de aprendizagem, tornando-o único e dinâmico, em que o aluno passa a ser o protagonista de seu processo de aprendizagem. Dessa forma, a robótica destaca-se como uma importante ferramenta pedagógica que faz parte da ideia de que o aluno pode "pôr a mão na massa", conforme a proposta do movimento Maker (ANDERSON, 2012).

A Robótica Educacional apresenta parte do viés desse movimento fazendo parte do Pensamento Computacional e da programação para a elaboração de projetos criativos com o "pensar como o computador", expressão apresentada por Papert (1993), uma vez que o computador se torna um recurso cognitivo para resolver problemas. De acordo com Jeannette Wing (2006), professora/cientista que inaugurou o termo Computational Thinking (Pensamento Computacional), destaca-se que este se baseia no poder e nos limites de processos de computação, quer eles sejam executados por um ser humano ou por uma máquina (WING, 2006, p. 33).

Nessa concepção, uma vez que a resolução de problemas e os princípios de sistemas se fundamentam em conceitos da área da Ciência da Computação, o Pensamento Computacional pode, portanto, contribuir como um instrumento para mudar a maneira com que as pessoas de diversas áreas resolvem problemas (CAMPOS, 2019).

\subsection{A Sala de Aula Invertida}

A inserção de metodologias ativas para uma educação inovadora apresenta, segundo Moran (2017), possibilidades de transformar aulas em experiências de aprendizagem mais criativas e significativas para o perfil da cultura digital. Dessa forma, a busca por metodologias para o uso pedagógico dos computadores ressignificando os papéis do aluno e do professor, com um ensino centrado no aluno, já vem acontecendo nas práticas educativas de diversos educadores.

Uma dessas metodologias é a Sala de Aula Invertida, que é uma metodologia de ensino híbrido que visa deslocar o papel do aluno de um estado passivo para um estado mais ativo de aprendizagem. Para que o aluno alcance o aprendizado esperado, é importante que ele assuma uma postura mais autônoma no seu processo de aprendizagem e realize os estudos indicados antes do encontro coletivo presencial ou síncrono com o professor e demais alunos de um curso. Otimiza-se, dessa forma, o tempo de aprendizagem do aluno e o tempo de ensino do professor. O acesso ao conhecimento básico fica, portanto, a cargo do aluno, havendo, ainda, estágios mais avançados de mediação do professor (BACICH e MORAN, 2018, p. 13).

O conceito básico de Sala de Aula Invertida envolve professores criando uma sala de aula virtual, disponibilizando materiais e atividades online para que os alunos estudem em casa. Isso permite aos professores avançarem diretamente para as atividades ativas de aprendizagem, baseadas no que os alunos aprenderam nas atividades virtuais (BERGMANN e SAMS, 2018).

Na Sala de Aula Invertida, cria-se um ambiente de aprendizagem sustentável, replicável e gerenciável, onde o aluno trabalha em tarefas diferentes e em momentos diferentes empenhados e engajados na própria aprendizagem, trazendo para a sua vida profissional "um modelo de aprendizagem para o domínio que ensina os alunos a assumirem a responsabilidade pela própria aprendizagem". Nessa perspectiva, Bergmann e Sams (2018, p. 56) destacam as seguintes características eficazes para o ensino no modelo de Sala de Aula Invertida:

- O professor deve dominar o conteúdo.

- O professor deve ser capaz de admitir quando não sabe a resposta para as perguntas dos alunos e precisa estar disposto a pesquisar a resposta com eles.

- O professor deve ser capaz de se movimentar durante a aula de maneira não linear.

- O professor precisa renunciar ao controle do processo de aprendizagem pelos alunos. 
Além dessas características, Bergmann e Sams (2018, p. 51) apresentam cinco principais componentes da Sala de Aula Invertida a serem desenvolvidos antes de se iniciar uma aula:

i. Definir os objetivos de aprendizagem de forma clara e os resultados esperados

ii. Identificar quais desses objetivos se alcançam com mais eficácia por meio de pesquisa ou de instrução direta.

iii. Vídeos podem ser utilizados para instrução direta focando nos objetivos determinados.

iv. Elaborar atividades criativas e cativantes para serem trabalhadas em sala de aula

v. Criar várias versões de cada avaliação somativa para que os alunos demonstrem o domínio de cada objetivo de aprendizagem em determinada unidade de estudo.

Um dos benefícios da Sala de Aula Invertida é uma maior eficiência no uso do tempo. Uma vez que uma aula invertida normalmente envolve assistir a versões em vídeo do material do curso online como dever de casa, os alunos podem então vir para aula no dia seguinte prontos para se envolverem ativamente no material (MARTÍN, 2017).

No entanto, em tempos em que o mundo vem sofrendo repentinas transformações sociais em decorrência da pandemia de COVID-19, esse modelo de Sala de Aula Invertida, neste trabalho, precisou ser ressignificado para essa nova realidade. Essa ressignificação foi distribuída em momentos síncronos e assíncronos de ensino remoto de robótica, uma vez que as pessoas se encontram em isolamento social e impossibilitadas de participarem de encontros coletivos com aulas presenciais. Com essa proposta, que emerge dentro de um contexto de pandemia, desconstruímos um entendimento do senso comum de que só é possível ensinar robótica presencialmente e com práticas utilizando kits com dispositivos mecânicos e elétricos de robótica.

\section{Oficina Online de Introdução à Robótica Educacional para Professores}

A ação de pesquisa proposta neste trabalho se concretizou em uma formação inicial de professores, tendo como sujeitos participantes da pesquisa professores da educação básica e da educação profissional e superior de diferentes áreas de conhecimentos.

Para a inscrição na Oficina Online de Introdução à Robótica Educacional, foi disponibilizado um formulário do Google Forms, onde foram selecionados os 40 primeiros candidatos. Esse limite de participantes foi definido conforme o número de tutores disponíveis para realizar o atendimento online no curso.

A oficina foi realizada totalmente online, durante 15 dias, na última quinzena de junho de 2020, com uma carga horária de 20 horas. Após o processo divulgação e inscrição, a oficina se desenvolveu ressignificando a Sala de Aula Invertida em momentos assíncronos, no ambiente virtual Moodle (Modular Object Oriented Distance Learning), e síncronos, no ambiente de webconferência da plataforma RNP. O objetivo do curso foi promover uma formação inicial de professores em Robótica Educacional, com um ensino centrado no aluno e desenvolvido com estratégias de inovação para promoção da aprendizagem criativa. Com essa proposta, possibilitamos uma integração do Pensamento Computacional, da programação e da eletrônica no desenvolvimento de projetos robóticos, conforme a área de atuação dos professores participantes da oficina.

\subsection{A Sala de Aula Invertida ressignificada no contexto de ensino remoto}

A formação de professores por meio da Oficina Online de Introdução à Robótica Educacional foi planejada no modelo híbrido de Sala de Aula Invertida ressignificada no contexto de Ensino Remoto de robótica. As atividades assíncronas e síncronas da oficina foram organizadas em duas semanas, conforme a Tabela 1, considerando os componentes da metodologia de Sala de Aula Invertida de Bergmann e Sams (2018, p. 51), apresentadas na Subseção 2.1. 
Tabela 1: Atividades síncronas e assíncronas para o desenvolvimento da formação.

\begin{tabular}{|c|c|c|c|c|}
\hline \multirow[b]{2}{*}{ Formação } & \multirow[b]{2}{*}{ Conceitos e Habilidades } & \multirow[b]{2}{*}{ Objetivos } & \multicolumn{2}{|c|}{ Atividades } \\
\hline & & & $\begin{array}{c}\text { Ferramentas, } \\
\text { Mídias }\end{array}$ & Tipo/Modo \\
\hline \multirow{3}{*}{$1^{\text {a }}$ Semana } & \multirow{3}{*}{$\begin{array}{c}\text { História da robótica, etapas } \\
\text { do método científico, } \\
\text { conceitos de cargas } \\
\text { elétricas. } \\
\text { Habilidades: } \\
\text { Compreender, } \\
\text { experimentar. } \\
\text { Robótica Educacional e } \\
\text { seus pilares, conceitos } \\
\text { básicos de elétrica, } \\
\text { simulador Tinkercad e suas } \\
\text { possibilidades. } \\
\text { Habilidades: Reproduzir, } \\
\text { compreender. } \\
\text { Definições e possibilidades } \\
\text { da plataforma e simulador } \\
\text { Tinkercad. } \\
\text { Habilidades: } \\
\text { Compreender. }\end{array}$} & \multirow{3}{*}{$\begin{array}{l}\text { Apresentar os objetivos da } \\
\text { disciplina e atividades } \\
\text { propostas. } \\
\text { Conhecer e refletir sobre a } \\
\text { história da robótica, seus } \\
\text { fundamentos e tipos de } \\
\text { robôs. } \\
\text { Conhecer a robótica no } \\
\text { contexto educacional, seus } \\
\text { pilares, conceitos básicos da } \\
\text { elétrica e simulador } \\
\text { Tinkercad. }\end{array}$} & $\begin{array}{c}\text { Moodle } \\
\text { Videoaula }\end{array}$ & $\begin{array}{c}\text { Fórum/ } \\
\text { Assíncrono }\end{array}$ \\
\hline & & & $\begin{array}{c}\text { Moodle } \\
\text { Videoaula }\end{array}$ & $\begin{array}{c}\text { Fórum/ } \\
\text { Assíncrono }\end{array}$ \\
\hline & & & $\begin{array}{c}\text { Moodle } \\
\text { Videoaula } \\
\text { Tinkercad }\end{array}$ & $\begin{array}{c}\text { Questionário/ } \\
\text { Assíncrono }\end{array}$ \\
\hline \multirow{3}{*}{$2^{\mathrm{a}}$ Semana } & \multirow{3}{*}{$\begin{array}{c}\text { Aula remota/Online com } \\
\text { ferramenta síncrona. } \\
\text { Habilidades: Interação e } \\
\text { colaboração. } \\
\text { Conceitos de Pensamento } \\
\text { Computacional, } \\
\text { programação por meio do } \\
\text { Tinkercad. Habilidades: } \\
\text { Compreender, resolver } \\
\text { problemas, pensar } \\
\text { computacionalmente. } \\
\text { Ferramentas e conceitos } \\
\text { básicos. Habilidades: } \\
\text { Compreender, aprender } \\
\text { fazendo. }\end{array}$} & \multirow{3}{*}{$\begin{array}{c}\text { Experimentar ferramenta } \\
\text { síncrona de comunicação } \\
\text { (webconferência). } \\
\text { Conhecer e compreender as } \\
\text { etapas do PC para resolução } \\
\text { de problema por meio } \\
\text { do simulador Tinkercad. } \\
\text { Conhecer os conceitos } \\
\text { elementares para elaboração } \\
\text { do projeto. }\end{array}$} & $\begin{array}{c}\text { Webconferência } \\
\text { Plataforma RNP } \\
\text { Tinkercad } \\
\text { Powerpoint } \\
\text { Youtube }\end{array}$ & $\begin{array}{l}\text { Simulação/ } \\
\text { Síncrono }\end{array}$ \\
\hline & & & $\begin{array}{c}\text { Moodle } \\
\text { Powerpoint } \\
\text { Tinkercad }\end{array}$ & $\begin{array}{c}\text { Fórum/ } \\
\text { Assíncrono }\end{array}$ \\
\hline & & & $\begin{array}{c}\text { Moodle } \\
\text { Tinkercad }\end{array}$ & $\begin{array}{c}\text { Tarefa/ } \\
\text { Assíncrono }\end{array}$ \\
\hline
\end{tabular}

Fonte: Elaboração própria, com base na pesquisa realizada.

Na primeira semana da oficina, iniciamos a formação de professores utilizando as ferramentas assíncronas do ambiente virtual Moodle, conforme os Componentes de $i$ a $v$ de Bergmann e Sams (2018, p. 51). Contemplando o Componente $i$, iniciamos o curso com um vídeo de apresentação da dinâmica da oficina, definindo os objetivos de aprendizagem. Para a pesquisa e instrução direta, conforme os Componentes ii e iii, disponibilizamos textos, vídeoaulas e fóruns de discussão para estudo dos conteúdos. Além disso, criamos um videotutorial para explicar a plataforma online e colaborativa Tinkercad, com um exemplo prático e sucinto de um projeto robótico. Para a avaliação somativa, contemplando o Componente $v$, criamos um questionário online com perguntas objetivas sobre a história da robótica, seus fundamentos, os tipos de robôs, a robótica 
no contexto educacional, os pilares da robótica (mecânica, eletrônica e programação) e os conceitos de eletricidade.

$\mathrm{Na}$ segunda semana da oficina, ocorreram momentos síncronos e assíncronos de aprendizagem online. Os momentos síncronos foram realizados em uma aula remota na plataforma de webconferência da RNP, havendo a transmissão ao vivo por meio do Youtube. Para essa aula, foi proposta uma sequência de atividades, conforme o roteiro da Tabela 2.

Tabela 2: Roteiro da aula remota/online com a ferramenta síncrona

\begin{tabular}{|l|l|}
\hline \multicolumn{1}{|c|}{ Momento } & \multicolumn{1}{c|}{ Descrição } \\
\hline Conhecendo o Tinkercad & $\begin{array}{l}\text { Apresentamos aos participantes, a ferramenta de criar } \\
\text { e simular circuitos Tinkercad, e os seus respectivos } \\
\text { recursos e funcionalidades. }\end{array}$ \\
\hline Conhecendo o Arduino e os seus componentes & $\begin{array}{l}\text { Apresentamos a placa Arduino, as possibilidades para } \\
\text { criação de projetos, e seus respectivos componentes. }\end{array}$ \\
\hline $\begin{array}{l}\text { Conhecendo os conceitos básicos de lógica } \\
\text { digital }\end{array}$ & $\begin{array}{l}\text { Apresentamos alguns conceitos sobre a lógica digital } \\
\text { e níveis lógicos binários. }\end{array}$ \\
\hline Conhecendo os conceitos básicos de eletricidade & $\begin{array}{l}\text { Foram apresentados conceitos, sobre Leds, resistores e } \\
\text { a relação entre corrente, tensão e resistência. }\end{array}$ \\
\hline Apresentação de um projeto no Tinkercad & $\begin{array}{l}\text { Explicamos e desenvolvemos um projeto com 2 Leds, } \\
\text { exemplificando os códigos em texto e blocos. }\end{array}$ \\
\hline Conhecendo o Pensamento Computacional & $\begin{array}{l}\text { Explicamos o Pensamento computacional, no } \\
\text { processo de pensamento envolvido na formulação de } \\
\text { um problema e na expressão de sua solução. }\end{array}$ \\
\hline Conhecendo os Pilares da Computação & $\begin{array}{l}\text { Foram apresentados os pilares, e os conceitos de } \\
\text { mecânica, eletrônica e programação. }\end{array}$ \\
\hline Possibilidades de uso da Robótica Educacional & $\begin{array}{l}\text { Apresentamos as possibilidades acerca do uso da } \\
\text { Robótica Educacional. }\end{array}$ \\
\hline
\end{tabular}

Fonte: Elaboração própria, com base na pesquisa realizada.

$\mathrm{Na}$ aula remota em modo síncrono, houve um encontro coletivo para construção e aplicação de um projeto no simulador Tinkercad. Nesse encontro, a proposta para a prática de robótica não consistiu em reproduzir passo-a-passos, mas sim em compreender e planejar um projeto de robótica na perspectiva dos conceitos do Pensamento Computacional.

Contemplando a Componente iv de Bergmann e Sams (2018, p. 51), para os momentos assíncronos da segunda semana, em ambiente Moodle, utilizamos textos, vídeos, fórum, tarefa e questionário para ensinar robótica por meio das etapas do Pensamento Computacional. Para tanto, utilizou-se de problemas do cotidiano, programação em blocos e montagem de pequenos projetos robóticos no simulador Tinkercad. Além disso, após a aula remota, os alunos participaram de uma atividade assíncrona via fórum do ambiente Moodle. A proposta dessa atividade era realizar um trabalho de concepção (e não de reprodução) dentro dos conceitos de decomposição, abstração, reconhecimento de padrões e algoritmo do Pensamento Computacional, com a finalidade de descrever uma solução para um projeto de robótica a ser desenvolvido no simulador Tinkercad.

Nessa proposta, foi solicitado que os alunos descrevessem uma sequência lógica de como fazer um projeto de sinal de trânsito sincronizado, conforme o exemplo reproduzido no simulador Tinkercad, mas de forma que eles tivessem que compreender e refletir em todos os passos na perspectiva de uma máquina. No final, eles participaram das discussões apresentando como pensaram computacionalmente no que aconteceria caso fosse invertida a ordem das instruções de um algoritmo, se o resultado seria o mesmo e porque a ordem correta de uma sequência de passos é essencial para o funcionamento correto de um projeto de automação.

A Figura 1 apresenta as atividades assíncronas apresentadas na Tabela 1 que foram disponibilizadas no ambiente Moodle durante a formação de professores. Cada uma dessas atividades é explicada na Tabela 3. 


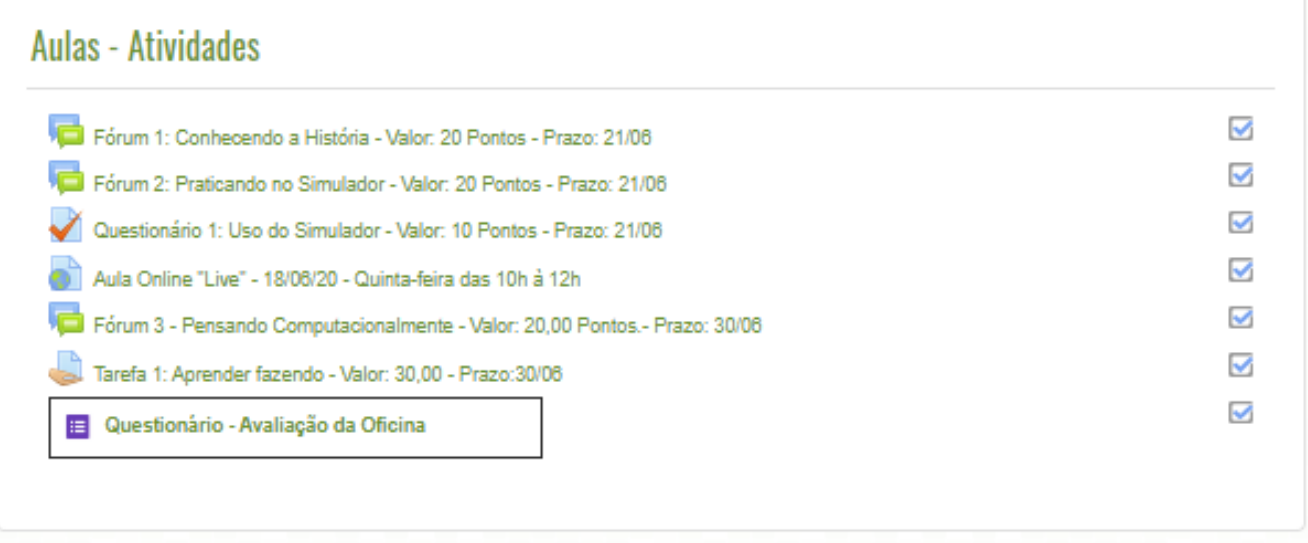

\section{Materiais Complementares}

Etapas do Método Cientifico

Aprofundando nos conceitos básicos de eletricidade na robótica

Figura 1: Ambiente Virtual de Aprendizagem da Oficina Online de Robótica Educacional.

Após "pensar computacionalmente" na solução de um problema de prática de robótica, na Tarefa Aprender Fazendo, isto é, "colocando a mão na massa", os alunos, por meio do simulador Tinkercad, desenvolveram um pequeno projeto de robótica. Como na atividade anterior, os alunos pensaram computacionalmente, planejando sua ação. Mas, dando um passo à frente, foi proposto que eles observassem como foram descritas as etapas planejadas e que criassem um passo-a-passo para representar a sequência lógica de resolução de um problema. No final, os alunos deveriam compartilhar seu projeto, falando da sua experiência durante o processo e contando como foi construir um projeto a partir dos conceitos do Pensamento Computacional e como o uso do simulador online Tinkercad pode auxiliar na aprendizagem de robótica.

A Figura 2 apresenta um pequeno projeto robótico com mecanismo de acendimento de vários leds, sendo possível a compreensão da estrutura como um todo a partir da parte física com a integração das peças (a placa protoboard, a placa arduíno, os resistores, os leds de várias cores, os fios condutores e a fonte de alimentação) e a partir da parte lógica, onde foi desenvolvida a sequência lógica com uma linguagem de programação em estrutura e/ou blocos. Esse projeto foi desenvolvido por meio da plataforma Tinkercad, durante a aula síncrona, com a explanação da estrutura física e lógica, realizando a simulação e apontando melhorias nos testes das partes.

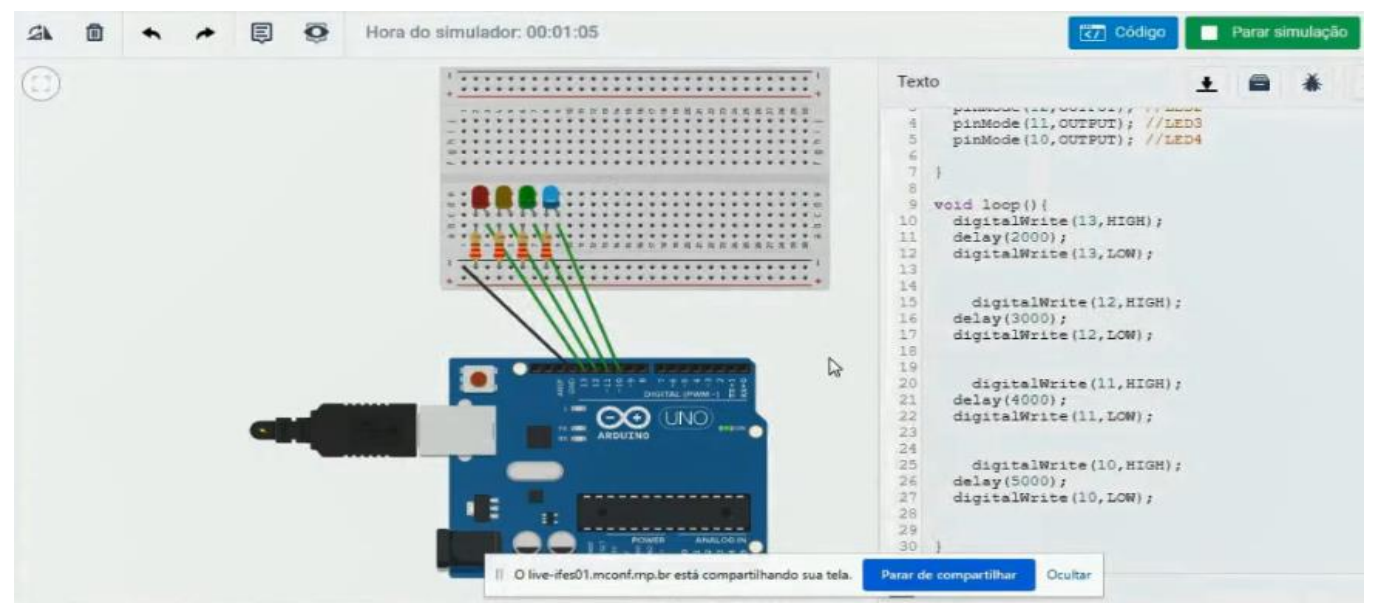

Figura 2: Exemplo de projeto desenvolvido no Tinkercad na Aula Online Síncrona. 
Tabela 3: Atividades da Tabela 1

\begin{tabular}{|c|l|}
\hline Atividades & \multicolumn{1}{c|}{ Descrição } \\
\hline 1 & $\begin{array}{l}\text { Fórum para realização do experimento de aplicação dos conceitos de } \\
\text { eletricidade e corrente elétrica. }\end{array}$ \\
\hline 2 & Reproduzir os conceitos de circuito elétrico no simulador Tinkercad. \\
\hline 3 & Questionário de avaliação dos conceitos introdutórios. \\
\hline 4 & $\begin{array}{l}\text { Planejamento de um projeto robótico a partir dos conceitos do Pensamento } \\
\text { Computacional. }\end{array}$ \\
\hline 5 & $\begin{array}{l}\text { Construção de um projeto no simulador Tinkercad a partir do planejamento } \\
\text { desenvolvido na Atividade 4. }\end{array}$ \\
\hline
\end{tabular}

\section{Resultados e Análise de Dados}

Nesta seção, são apresentados os resultados obtidos a partir da catalogação dos dados coletados nos questionários e atividades da Oficina Online de Introdução à Robótica Educacional executada em modo ressignificado de Sala de Aula Invertida em momentos assíncronos e síncronos de ensino remoto. Mais especificamente foram analisados: i) a experiência e conhecimentos prévios dos professores participantes da formação, ii) os conhecimentos demonstrados antes, durante e depois da introdução do Pensamento Computacional e do desenvolvimento de projetos robóticos no simulador Tinkercad, iii) os resultados obtidos a partir da formação.

\subsection{Resultados obtidos a partir do questionário de inscrição dos professores}

Nesta seção apresentamos as impressões dos professores por meio de relatos apresentados nas atividades quanto aos conhecimentos adquiridos, às dificuldades, aos êxitos de aprendizagem como também quanto às motivações dos alunos.

De acordo com os dados coletados no questionário de inscrição dos professores, a formação obteve uma taxa de participação dos alunos em torno de $76 \%$, sendo que $50 \%$ dos inscritos finalizaram a formação e $26 \%$ evadiram, o restante, isto é, $24 \%$ dos inscritos receberam o acesso à plataforma, mas não a acessaram, conforme o gráfico da Figura 3. Quanto aos problemas de evasão e de não acesso ao curso, como estratégia para minimizar as desistências, uma possibilidade para a próxima oferta do curso seria iniciá-lo com um encontro síncrono para dar uma formação inicial de ambientação dos participantes menos experientes ao ambiente virtual de aprendizagem Moodle.

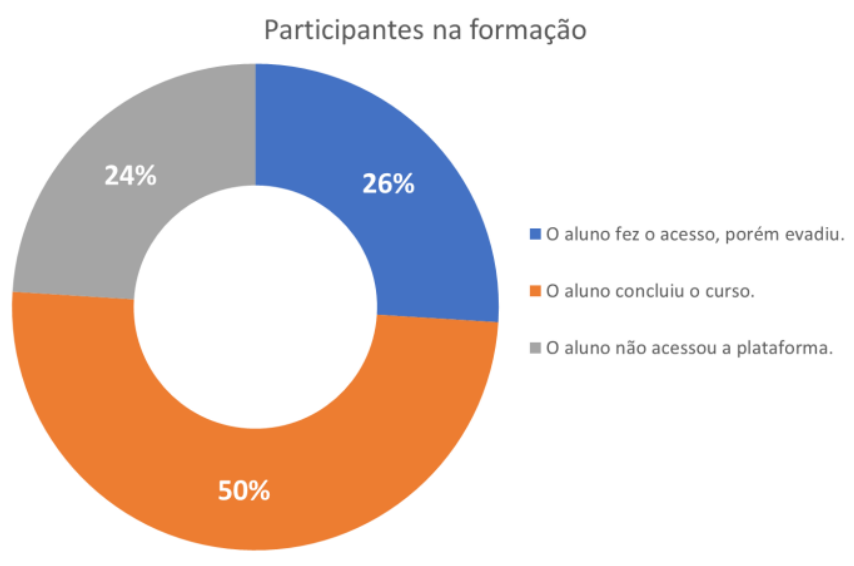

Figura 3: Participantes selecionados para a Oficina Online de Introdução à Robótica. 
O primeiro bom resultado alcançado pela oficina online foi no processo de inscrições. Nesse processo, obtivemos 566 inscritos para 40 vagas. Desse total de inscritos, foram chamados 60 candidatos para preenchimento das vagas, pois alguns candidatos não conseguiram acessar o curso e os suplentes foram chamados.

As inscrições para a oficina vieram de diversas regiões do país, dentre as quais, destacamos a região sudeste com $66 \%$, a Região Norte com 14\%, a Região Nordeste com $9 \%$, a Região Sul com $8 \%$ e a Região Centro-Oeste com 3\%. Essa diversidade de regiões também aconteceu entre os 60 professores chamados para o preenchimento das vagas, no entanto, houve um predomínio de participantes da Região Sudeste, principalmente do Estado do Espírito Santo.

Quanto aos conhecimentos prévios em Pensamento Computacional e programação, 74,3\% do total de inscritos no curso responderam que possuem um conhecimento básico ou nenhum conhecimento; $19,5 \%$ responderam que possuem conhecimento intermediário; e somente $6,2 \%$ declararam que possuem conhecimentos avançados. Procuramos também compreender a necessidade de formação dos professores selecionados e obtivemos os seguintes resultados: $85,5 \%$ disseram que precisavam muito aprender sobre o assunto ou que tinham curiosidade de aprendê-lo, e apenas $14,5 \%$ dos inscritos respondeu que foi porque precisavam do certificado para progressão de carreira ou por outros motivos.

A partir desses resultados do questionário de inscrição, percebemos uma alta procura pelo curso em um curto período de tempo, o que evidenciou o ensino online de robótica como um conhecimento de interesse popular com alta procura, mas ainda com carência de oferta de vagas. Além disso, o número de inscrições nesta formação foi um indicador que revelou a importância da formação em Robótica Educacional, especialmente em tempos de pandemia, em que muitas possibilidades de oferta de cursos de formação têm sido abandonadas, uma vez que a grande maioria acontece de forma presencial e com necessidade de práticas em laboratório com kits específicos de Robótica Educacional.

\subsection{Resultados do questionário de avaliação da Oficina Online de Introdução à Robótica}

Dos 60 professores que foram chamados para o preenchimento das 40 vagas da Oficina Online de Introdução à Robótica, 30 foram certificados. Os professores que concluíram a oficina foram convidados a avaliarem o curso por meio de um questionário, a partir do qual foi possível coletar e analisar as respostas sobre avaliação, sugestões e críticas quanto à formação, conforme os gráficos da Figura 4. 

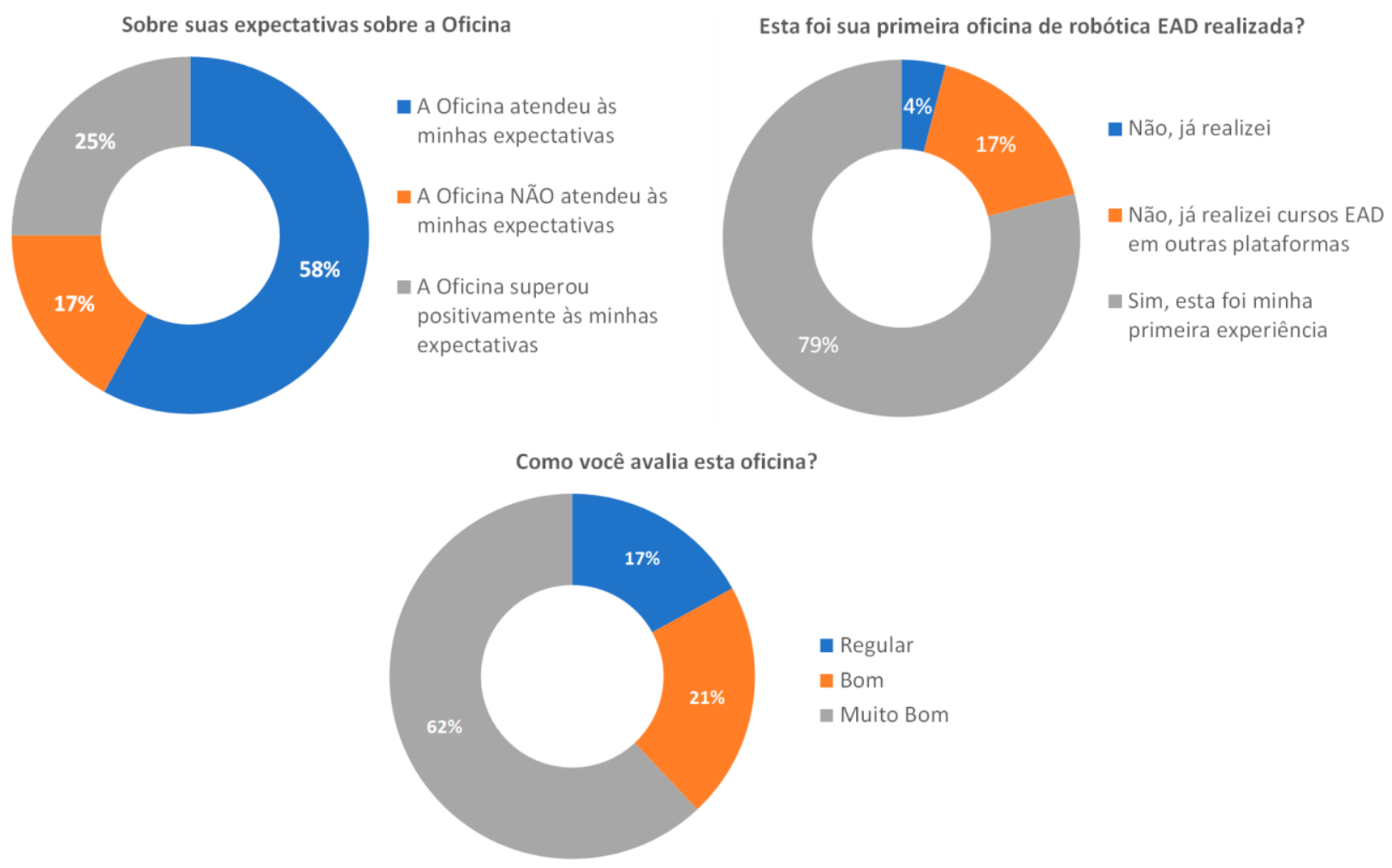

Figura 4: Questionário de avaliação final da oficina online.

Em uma avaliação da formação realizada através da Oficina Online de Introdução à Robótica Educacional, conforme indicado no gráfico da Figura 4, obtivemos os seguintes resultados de avaliação: $83 \%$ avaliaram a oficina como bom e muito bom e $17 \%$ dos formandos avaliaram a oficina como regular. Quanto às expectativas em relação à formação online em Robótica Educacional, obtivemos os mesmos resultados, isto é, $83 \%$ dos formandos responderam que a oficina superou as expectativas e que atendeu às suas expectativas e $17 \%$ responderam que não atendeu às suas expectativas. Considerando essas respostas, para atender melhor as expectativas dos estudantes, consideramos necessário em projetos futuros deixar mais claros na chamada pública para qual público-alvo se destina a oficina (que é de pessoas inexperientes em robótica), assim como destacar que o nível de profundidade da formação em robótica seria introdutório.

Também constatamos que a oficina foi a primeira experiência para $79 \%$ dos professores inscritos nessa modalidade online de ensino de robótica, que somente $17 \%$ já obteve essa experiência em plataforma online e que apenas 4\% já realizou uma formação a distância de Robótica Educacional. Vale ressaltar que 50\% desses professores atuam nas áreas de Ciências Exatas, 27\% nas Ciências Humanas e 23\% nas Ciências Biológicas, o que caracteriza uma diversidade de perfis de atuação que têm buscado formação em Robótica Educacional. Os dados, sugerem, portanto, que há uma carência de estratégias de ensino de robótica na modalidade de ensino remoto e a distância.

Os gráficos da Figura 5, a seguir, apresentam os rendimentos dos alunos por nota em cada atividade da Tabela 3. Observamos que a maioria dos alunos alcançaram notas máximas na maioria das atividades, evidenciando êxitos de aprendizagem nessa proposta de formação inicial e online de professores em Robótica Educacional. 


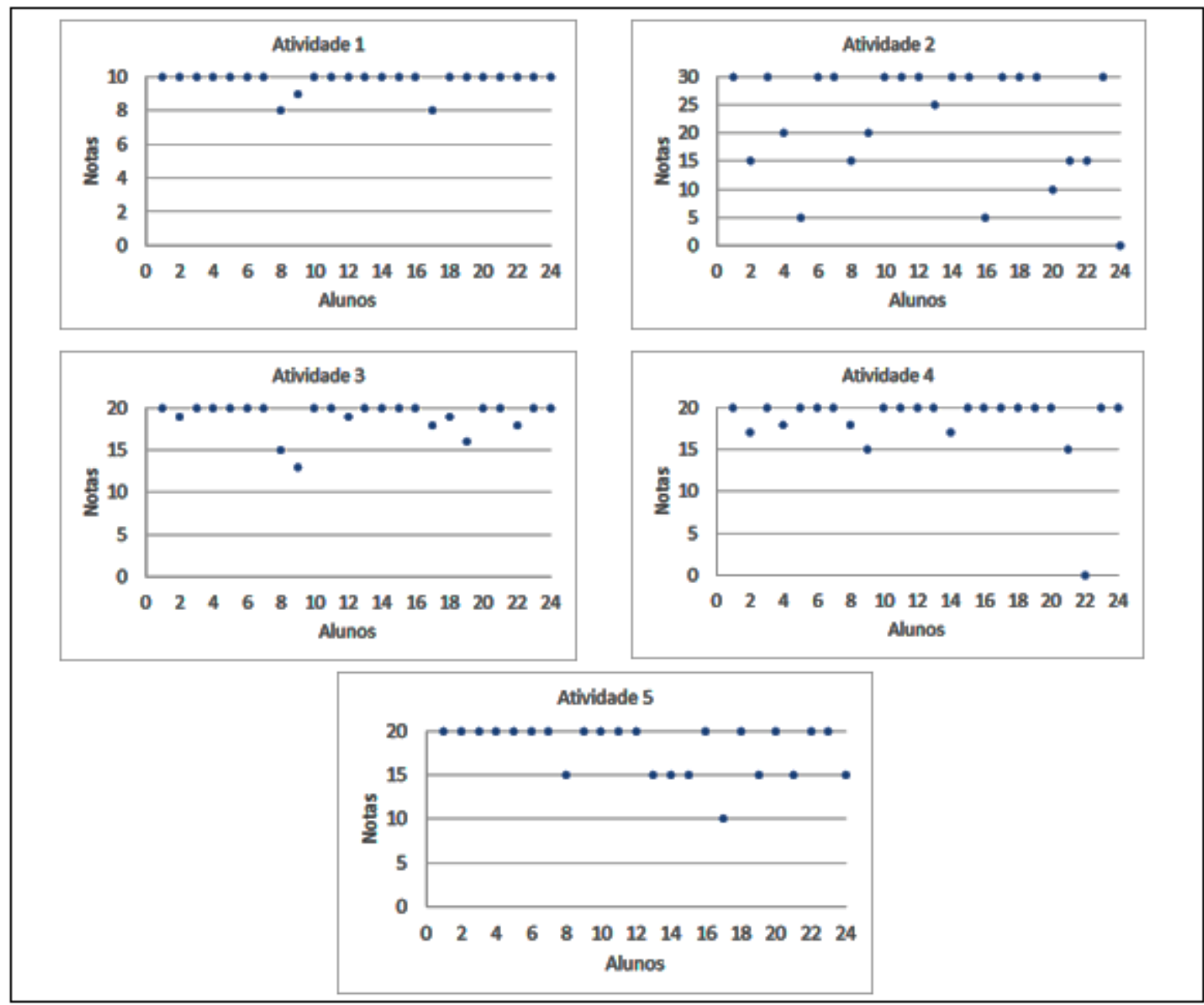

Figura 5: Rendimento dos alunos.

Uma importante observação nos gráficos de desempenhos da Figura 5 é em relação às atividades 2, 3, 4 e 5, que evidenciam uma evolução dos alunos após a aula remota em modo síncrono realizada via webconferência com práticas no simulador online Tinkercad.

Na Figura 5, conforme a diversidade de desempenhos, observamos que houve dificuldades na realização da Atividade 2 com o uso do simulador Tinkercad. Embora nessa atividade fossem apresentados os pilares da robótica e seus conceitos de forma que fosse possível reproduzi-los e fazer associações na prática em simulador, houve a necessidade de um direcionamento mais pedagógico para a atividade. Dessa forma, entre as Atividades 3 e 4, realizamos uma aula remota, em modo síncrono pela plataforma de webconferência RNP, apresentando um exemplo prático de projeto robótico no simulador Tinkercad, os conceitos do Pensamento Computacional e os pilares da robótica.

Após a aula remota, na Atividade 4, foi apresentado aos alunos um problema real enfrentado pelas grandes cidades que é a falta de sincronismo dos sinais de trânsito e os impactos que esse problema causa na mobilidade urbana. Nessa atividade, o objetivo era compreender o funcionamento de um sinal de trânsito e como poderíamos utilizar os conceitos do Pensamento Computacional para resolver o problema apresentado planejando por meio de uma sequência lógica para criar um sinal de trânsito sincronizado no simulador online Tinkercad. Inicialmente, percebemos que os alunos já demonstravam possuir maior familiaridade com os conceitos, uma vez que eles já haviam sido introduzidos na aula remota em modo síncrono. No entanto, ainda era algo muito novo e desafiador para eles desenvolver uma sequência lógica para estruturar um algoritmo para resolução de problemas. Mas, ainda assim, houve evolução de desempenhos, conforme os resultados da Atividade 4 na Figura 5. 
Por fim, na Atividade 5, conforme a Figura 5, os alunos mostraram melhores resultados de concepção e prática no simulador e nas associações dos pilares da robótica fazendo o uso do conceito do Pensamento Computacional para desenvolver a solução planejada na Atividade 4 para o problema de sincronia de sinal de trânsito. Observamos, portanto, que houve melhor aprendizado desenvolvendo um projeto não a partir de um passo-a-passo, mas sim a partir do desenvolvimento de uma sequência lógica compreendida e desenvolvida na perspectiva dos conceitos do Pensamento Computacional.

Na Tabela 4, apresentamos uma análise da evolução de desempenhos da Atividade 2 para as atividades 4 e 5, fazendo uma relação entre elas e a análise dos rendimentos apresentados na Figura 5. Nessa análise, concluímos que os desempenhos dos participantes foram melhorando após a aula remota com o encontro síncrono à medida que as soluções das atividades, mesmo ficando mais complexas, foram sendo melhor compreendidas e refletidas a partir dos conceitos do Pensamento Computacional e aplicadas em um simulador de projetos robóticos.

Tabela 4: Comparação das atividades

\begin{tabular}{|c|c|c|}
\hline \multicolumn{3}{|c|}{ Progressão nas Atividades } \\
\hline Atividade 2 & Atividade 4 & Atividade 5 \\
\hline $\begin{array}{l}\text { Nesta atividade utilizamos a } \\
\text { reprodução de um projeto } \\
\text { envolvendo os principais } \\
\text { conhecimentos de projetos } \\
\text { robóticos como, por } \\
\text { exemplo: Pensamento } \\
\text { Computacional, } \\
\text { programação e eletrônica. }\end{array}$ & $\begin{array}{l}\text { Introduzimos esta atividade com um problema } \\
\text { real da sociedade para apresentação de possíveis } \\
\text { soluções utilizando para isso o recurso fórum } \\
\text { como um meio de trocas de informações e } \\
\text { reflexões. Neste momento, aplicamos, a partir } \\
\text { dos conceitos do Pensamento Computacional, } \\
\text { uma atividade para planejar em forma de texto } \\
\text { um passo-a- passo para criação de uma solução } \\
\text { para um problema. }\end{array}$ & $\begin{array}{l}\text { Dando continuidade à Atividade } \\
\text { 4, partimos para a construção do } \\
\text { projeto de robótica planejado, } \\
\text { agora em um contexto online } \\
\text { utilizando simulador aplicando } \\
\text { os conceitos do Pensamento } \\
\text { Computacional. }\end{array}$ \\
\hline $\begin{array}{l}\text { Observamos quanto aos } \\
\text { rendimentos, conforme a } \\
\text { Atividade } 2 \text { na Figura } 5 \text {, uma } \\
\text { maior variação das notas dos } \\
\text { participantes, o que } \\
\text { evidencia dificuldades na } \\
\text { reprodução dos projetos. } \\
\text { existentes e nos conceitos } \\
\text { envolvido nesses projetos. }\end{array}$ & $\begin{array}{l}\text { Nessa atividade, observamos uma maior } \\
\text { estabilidade com menor variação de notas, } \\
\text { conforme a Atividade } 4 \text { na Figura 5. Isso } \\
\text { evidencia uma maior compreensão e mais } \\
\text { facilidade nos passos de desenvolvimento de } \\
\text { uma solução, ao contrário da Atividade } 2 \text {, em que } \\
\text { se reproduzia uma solução com pouca } \\
\text { compreensão e reflexão dos passos que foram } \\
\text { desenvolvidos. }\end{array}$ & $\begin{array}{l}\text { Nesta atividade, podemos } \\
\text { observar, conforme Atividade } 5 \\
\text { na Figura } 5 \text {, um número bem } \\
\text { maior de participantes com notas } \\
\text { altas e nenhum a nota baixa. Isso } \\
\text { evidencia uma melhor } \\
\text { compreensão ao desenvolver um } \\
\text { projeto na perspectiva dos } \\
\text { conceitos do Pensamento } \\
\text { Computacional e não por meio } \\
\text { de um passo-a-passo para } \\
\text { reprodução. }\end{array}$ \\
\hline
\end{tabular}

Fonte: Elaboração própria, com base na pesquisa realizada.

Dessa forma, a aula remota com encontro síncrono funcionou como uma intervenção que possibilitou avanços nos desempenhos dos participantes, conforme a Tabela 4 e a Figura 5 . O impacto dessa aula remota consistiu, portanto, em ajudar professores a compreenderem e refletirem o processo de desenvolvimento de projetos robóticos a partir dos conceitos do Pensamento Computacional nas práticas online de robótica através de um simulador.

Mostramos assim que a estratégia de Sala de Aula Invertida, desenvolvida em modos síncrono e assíncrono com atividades de aprendizagem ativa e práticas em simulador, promoveu êxitos de aprendizagem pelos professores em formação. Isso porque essa estratégia levou os professores à compreensão, ao planejamento e à reflexão dos processos de desenvolvimento de um projeto robótico em uma abordagem dirigida a partir dos conceitos do Pensamento Computacional e dos pilares robótica, conforme os resultados de desempenhos da Figura 5. 
A estratégia utilizada contribuiu para uma melhor assimilação, associação e aplicação dos conteúdos de robótica ensinados. Dessa forma, entendemos que ensinar robótica da concepção do Pensamento Computacional à programação e automação de soluções poderá impactar em êxitos de aprendizagem se reproduzida da mesma forma nas práticas educativas desses professores.

Concluindo, a Tabela 5 apresenta alguns dos depoimentos dos professores que participaram da Oficina Online de Introdução à Robótica Educacional. De acordo com esses depoimentos e os resultados de desempenhos dos professores em formação nas atividades do curso, e conforme a Figura 5, evidenciam-se êxitos na aplicação da metodologia de Sala de Aula Invertida ressignificada para o contexto de ensino remoto de Robótica Educacional em uma formação de professores realizada totalmente online.

Tabela 5 - Depoimentos de Professores

\begin{tabular}{|c|c|}
\hline Pergunta & Depoimentos \\
\hline $\begin{array}{l}\text { Quais mudanças } \\
\text { ocorreram ou } \\
\text { podem ocorrer } \\
\text { na sua prática } \\
\text { pedagógica após } \\
\text { a conclusão } \\
\text { dessa formação? }\end{array}$ & $\begin{array}{l}\text { "Posso incluir agora a programação em minhas aulas de forma facilitada com o Tinkercad", } \\
\text { "Aprendi uma didática bacana para o ensino e a relembrar o uso da plataforma Tinkercad", } \\
\text { "Com toda certeza estudarei mais sobre a interface Tinkercad e levarei para minha prática } \\
\text { com crianças", "Me forneceu ideias para trabalhar com os alunos" e "poder criar um } \\
\text { ambiente mais lúdico e interativo para a aprendizagem de robótica, principalmente pela } \\
\text { plataforma Tinkercad, e também um novo olhar quanto à ciência e tecnologia como um mundo } \\
\text { de descoberta e investigação, com práticas e experimentos para o entendimento de conceitos } \\
\text { físicos e químicos de maneira simples e divertida". }\end{array}$ \\
\hline $\begin{array}{l}\text { Contribua com } \\
\text { elogios/críticas e } \\
\text { sugestões }\end{array}$ & $\begin{array}{l}\text { "Já fiz alguns cursos de Arduino, inclusive no Tinkercad. Mas o maior problema que todos } \\
\text { eles eram introdução a robótica, minha dica é criar vários cursos de robótica com níveis } \\
\text { diferente,", "A formação foi extremamente enriquecedora. Toda a explicação foi de forma } \\
\text { simples", "gostei da prestatividade dos professores", "Parabéns a todos...foi muito didática } \\
\text { e esclarecedora", "foi excelente...", "no geral, gostei da formação", "sugiro elaborar um } \\
\text { curso para entender a parte elétrica básica, um curso que seja voltado para pessoas que não } \\
\text { têm vasto conhecimento no assunto e precisam desse conteúdo para avançar no uso dessa } \\
\text { ferramenta. Sugestão é priorizar as pessoas que fizeram este curso de Robótica Educacional", } \\
\text { "só elogiar, foi uma formação bem tranquila e uma ótima iniciativa, para despertar o gosto } \\
\text { pela robótica e adquirir novos conhecimentos e ferramentas.", "parabéns pela iniciativa, é } \\
\text { preciso aprofundar um pouco mais.", "Excelente! Ótimos professores! Parabéns!" e "adorei } \\
\text { o curso deixo como sugestão de um curso de especialização em Robótica Educacional”. }\end{array}$ \\
\hline
\end{tabular}

Fonte: Elaboração própria, com base na pesquisa realizada.

\section{Conclusão}

Este trabalho apresentou uma proposta de formação inicial de professores através da Oficina Online de Introdução à Robótica Educacional, com a proposta de ressignificação do modelo de Sala de Aula Invertida para o ensino remoto distribuído em momentos síncronos e assíncronos. Objetivou-se através dessa proposta de formação promover uma reflexão e uma reorientação de estratégias de inovação nas práticas educativas para preparar professores para mediação através dos conceitos do Pensamento Computacional, da programação em blocos e da construção de pequenos projetos robóticos no simulador online e colaborativo de Arduíno Tinkercad.

A estratégia de ressignificação da sala de aula invertida para uma formação em Robótica Educacional totalmente online veio desconstruir um entendimento do senso comum de que só é possível ensinar robótica presencialmente e com práticas utilizando kits com dispositivos mecânicos e elétricos de robótica. Observamos também que os participantes da oficina apreciaram a forma como foi conduzida a formação de professores: totalmente online, tendo como base os 
três pilares da robótica (mecânica, eletrônica e programação) e, principalmente, por meio da produção de projetos robóticos utilizando o simulador Tinkercad, o que possibilitou que as atividades práticas de robótica fossem realizadas remotamente.

As principais limitações observadas nessa primeira oferta da Oficina Online de Introdução à Robótica Educacional foram as seguintes: não atender à alta demanda de inscritos por limitação da quantidade de tutores disponíveis para acompanhar os participantes, não oferecer uma aula remota de encontro síncrono para ambientação ao Moodle e ter sido um curso introdutório de curta duração (20 horas). Para reduzir essas limitações, estamos desenvolvendo uma proposta de ensino híbrido baseada em Mooc (Massive Open On-line Course) com disponibilidade de acesso durante o período de seis meses para conclusão do curso, com oferta ilimitada de vagas, sem tutoria e com mais encontros síncronos para atendimento aos participantes.

Quanto às lições aprendidas, a principal delas é que as atividades metacognitivas, isto é, aquelas em que os participantes de um curso compreendem e refletem sobre os próprios passos no processo de aprendizagem aplicando os conteúdos estudados, muito contribuem para uma aprendizagem ativa e significativa. Entre outras lições aprendidas, destacamos a criação ou ressignificação de estratégias de ensino, tradicionalmente desenvolvidas em modo presencial, para o contexto de ensino totalmente online, e o uso de tecnologias e de metodologias ativas para o desenvolvimento das habilidades do Pensamento Computacional.

Concluímos, a partir dos resultados alcançados, que a formação de professores em introdução à Robótica Educacional, no contexto de ensino remoto, consolidou-se em sucessos de aprendizagem. Nossas expectativas são, portanto, que essa estratégia simples de aprendizagem ativa, com a inovação de ressignificação da Sala de Aula Invertida no contexto de ensino remoto de Robótica Educacional em tempos de pandemia de Covid-19, possa ser uma referência para outras ações de formação de professores. Além disso, esperamos que novos cursos ampliem as possibilidades desta proposta, favorecendo formações em larga escala e avanços nas metodologias de ensino remoto de Robótica Educacional.

\section{Referências}

Alimisis, D. (2013). Educational robotics: Open questions and new challenges. Themes in Science and Technology Education. 6(1). 63-71. [GS Search]

Anderson, C. (2012). Makers: a nova revolução industrial. Tradução de: SERRA, ACC Rio de Janeiro: Elsevier.

Bacich, L., \& Moran, J. (2018). Metodologias ativas para uma educação inovadora: uma abordagem teórico-prática. Penso Editora.

Bergmann, J., \& Sams, A. (2018). Sala de aula invertida: Uma metodologia ativa de aprendizagem. Rio de Janeiro: LTC.

Campos, F. R. (2019). A Robótica para Uso Educacional - São Paulo: Ed. Senac São Paulo.

Gomes, A. S. A., Da Silva, J. F., \& Teixeira, L. R. D. L. (2020). Educational Robotics in Times of Pandemic: Challenges and Possibilities. In 2020 Latin American Robotics Symposium (LARS), 2020 Brazilian Symposium on Robotics (SBR) and 2020 Workshop on Robotics in Education (WRE) (pp. 1-5). IEEE. doi: 10.1109/LARS/SBR/WRE51543.2020.9307145 [GS $\underline{\text { Search] }}$

Lima, W. F. (2016). Aprendizagem colaborativa para o ensino de química por meio da robótica educacional (UFG), Disponível em: http://repositorio.bc.ufg.br/tede/handle/tede/6165 [GS Search] 
Moran, J. M. (2017) Mudando a educação com metodologias ativas. Coleção Mídias Contemporâneas. Convergências Midiáticas, Educação e Cidadania: aproximações jovens, v.2.

Papert, S. (1993). The Children's Machine: Rethinking School in the Age of the Computer. New York: Basic Books.

Papert, S. (1994). Máquina das Crianças: Repensando a Escola na Era da Informática. Porto Alegre: Artes Médicas.

Papert, S. (1997). A família em rede: ultrapassando a barreira digital entre gerações. Título original: The Connected Family: bridging the digital generation gap. Lisboa: Relógio D’Água Editores.

Queiroz, R. L., \& Sampaio, F. F. (2016). DuinoBlocks for Kids: Um ambiente de programação em blocos para o ensino de conceitos básicos de programação a crianças do Ensino Fundamental I por meio da Robótica Educacional. Anais do XXXVI CSBC. Porto Alegre: PUC-RS. p. 2086-2095. doi: 10.5753/wei.2016.9652 [GS Search]

Rehman, R., \& Fatima, S. S. (2021). An innovation in Flipped Class Room: A teaching model to facilitate synchronous and asynchronous learning during a pandemic. Pakistan Journal of Medical Sciences, 37(1), 131. doi: 10.12669/pjms.37.1.3096 [GS Search]

Tselegkaridis, S., \& Sapounidis, T. (2021). Simulators in Educational Robotics: A Review. Education Sciences, 11(1), 11. 10.3390/educsci11010011 [GS Search]

Wing, J. M. (2006). Computational thinking. Communications of the ACM, v. 49, n. 3, p. 33-35. Disponível em: https://www.cs.cmu.edu/ 15110-s13/Wing06-ct.pdf. doi: $\underline{10.1145 / 1118178.1118215}$ [GS Search] 